\title{
Long-term tumour outcomes of self-expanding metal stents as 'bridge to surgery' for the treatment of colorectal cancer with malignant obstruction: a systematic review and meta-analysis
}

\author{
Yinghao Cao ${ }^{1}$ Junnan $\mathrm{Gu}^{1} \cdot$ Shenghe Deng ${ }^{1} \cdot$ Jiang $\mathrm{Li}^{1} \cdot \mathrm{Ke} \mathrm{Wu}^{1} \cdot \mathrm{Kailin}^{\mathrm{Cai}}{ }^{1}$
}

Accepted: 23 August 2019 / Published online: 12 September 2019

(C) The Author(s) 2019

\begin{abstract}
Purpose To explore the long-term oncological results of self-expanding metal stents (SEMS) as a surgical transition compared with those of simple emergency surgery.

Methods A systematic review of studies involving long-term tumour outcomes comparing SEMS with emergency surgery was conducted. All studies included information on 3-year and 5-year survival rates, 3-year and 5-year disease-free survival (DFS) rates, and local and overall recurrence rates; the results were expressed as odds ratios.

Results Overall, 24 articles and 2508 patients were included, including 5 randomised controlled trials, 3 prospective studies, and 16 retrospective studies. The 3-year survival rate (odds ratio $(\mathrm{OR})=0.88,95 \%$ confidence interval $(\mathrm{CI}) 0.69-1.12, P=0.05$ ), 5 -year survival rate $(\mathrm{OR}=0.91,95 \% \mathrm{CI} 0.70-1.17, P=0.67), 3$-year $\mathrm{DFS}$ rate $(\mathrm{OR}=1.14,95 \% \mathrm{CI} 0.91-1.42, P=0.65), 5$-year DFS rate $(\mathrm{OR}=1.35,95 \% \mathrm{CI} 0.91-2.02, P=0.17)$, overall recurrence rate (OR 1.04, 95\% CI 0.77-1.41, $P=0.14)$, and local recurrence rate (OR 1.37, 95\% CI 0.84-2.23, $P=0.92$ ) were determined. There was no significant difference between the randomised and observational studies in the subgroup analysis, and the 5-year survival rate was higher in studies with a stent placement success rate of $\geq 95 \%$. Conclusion SEMS implantation was a viable alternative in malignant left colon obstruction as a transition to surgery; its longterm survival results, including 5-year DFS and overall survival, were equivalent to those of emergent surgery.
\end{abstract}

Keywords Self-expanding metal stents $\cdot$ Emergency surgery $\cdot$ Colorectal cancer $\cdot$ Malignant obstruction $\cdot$ Long-term oncological results

\section{Introduction}

Colorectal cancer is currently one of the most common malignant tumours, ranking third in incidence and second in mortality. According to incomplete statistics, there are more than 1.8 million new cases and 881,000 deaths are estimated to occur in 2018 [1]. Acute intestinal obstruction is a common complication of abdominal tumours. It is estimated that $7 \%$ to

Yinghao Cao, Junnan Gu and Shenghe Deng contributed equally to this work and they were considered co-first authors.

$\mathrm{Ke} \mathrm{Wu}$

wuke201288@126.com

Kailin Cai

caikailin@ hust.edu.cn

1 Department of Gastrointestinal Surgery, Union Hospital, Tongji Medical College, Huazhong University of Science and Technology, Wuhan 430022, Hubei, China
$29 \%$ of all colorectal cancer patients have partial or complete intestinal obstruction, and about $70 \%$ of cases occur in the left colon $[2,3]$. If not treated in time, fatal complications are likely to occur [3-6]. In case of acute obstruction, the traditional treatment method is emergent ostomy or intraoperative intestinal lavage after preventive ostomy, followed by radical resection or ostomy reversion surgery. Compared with elective colorectal surgery, the complications and mortality of patients are very high due to the poor patient condition and high surgical risk [7, 8]. In the early 1990s, Dohmoto first proposed the use of self-expanding stents as a new method for the treatment of malignant colonic obstruction. Tejero et al. reproted the initial experience with self-expanding metal stents (SEMS) to relieve obstruction in advanced colon cancer, which opened a new chapter in the treatment of colorectal cancer complicated with malignant obstruction $[9,10]$. SEMS placement can effectively relieve obstruction and be used both as emergency and elective surgery, allowing patients with optimised clinical conditions to undergo selective 
laparoscopic resection to avoid stoma [11]. If a thorough evaluation after stent placement indicates the presence of an irresectable tumour, a surgical procedure would therefore be avoided. A number of prospective controlled studies and meta-analyses have shown that SEMS has a good short-term effect as a bridge to surgery (BTS) compared with emergency surgery [12-14]. Although the short-term benefits of SEMS as a BTS have been established in recent years, the promotion of metastasis caused by stent implantation remains suspected due to blood dissemination produced by tumour compression [15]. In case of perforation, the increase in peritoneal implantation is also plausible. The long-term survival results remain controversial [15-21]. This systematic review aims to explore the long-term oncological results of SEMS as a surgical transition compared with simple emergency surgery.

\section{Methods}

\section{Search strategy and study selection}

This study was approved by the Ethics Committee of the Tongji Medical College, Huazhong University of Science and Technology. A systematic literature search was conducted in the databases of Medline (PubMed), Embase (Ovid), and Cochrane libraries until January 2019. The following terms were used in conjunction or in combination: colonic stents, self-expanding stents, stents as a bridge to surgery, malignant intestinal obstruction, acute intestinal obstruction, and long-term tumour outcomes.

\section{Inclusion/exclusion criteria and data extraction}

The titles and abstracts of all retrieved references were independently reviewed by two investigators. Titles and abstracts identified as potentially relevant were included in the full-text analysis and selected if they met the inclusion criteria.

Studies that met the following criteria were considered eligible for inclusion: a comparative study of SEMS and emergency surgery; reporting at least one long-term tumour outcome measure (overall survival rate, disease-free survival rate, or any type of relapse rate); all patients involved in the study must have resectable tumours; and an average follow-up time of at least 3 years. Studies with the following features were excluded: written in a language other than English; comparing BTS and emergency surgery in both the left and right colon; unable to extract accurate measurement data; simple rectal cancer obstruction and palliative treatment; case reports, letters, and reviews.

Firstly, randomised trials and prospective or retrospective comparison cohort studies were selected to maximise patient numbers. For each study, the name of the lead author, the year of publication study, design, duration, number of participating centres, number of patients, median follow-up, and baseline characteristics were retrieved.
The primary outcome was overall survival at 3 and 5 years; secondary outcomes were 3 -year and 5 -year disease-free survival, total recurrence, and local recurrence. If the study only provided a Kaplan-Meier survival curve rather than an absolute survival rate, we estimated the incidence from the survival curve with the highest accuracy and then calculated the number of events, and the subgroup analysis should include study location, number of participants, year of publication, and other indicators [22]. Data were extracted by a researcher (YH C) to improve standardisation and reviewed by a second researcher (JN G) to resolve differences until a consensus was reached; if there was a disagreement, the third author (KL C) would make the final decision.

\section{Statistical analysis}

Pooled odds ratios (OR) with $95 \%$ confidence intervals $(95 \%$ CI) for local and overall recurrence, 3-year and 5-year survival rates, and DFS were calculated using a random effects model. A meta-analysis was performed using Review Manager (RevMan) Version 5.3 for Windows (the Cochrane Collaboration 2012, Denmark). Dichotomous variables were analysed by assessing the risk ratio (RR) of an adverse event occurring with BTS compared with the emergency surgery group along with $95 \%$ confidence intervals (95\% CIs). An OR $<1$ favoured the SEMS as BTS group. The point estimate OR was considered statistically significant when the $p$ value was $<0.05$ and the $95 \%$ CI did not include the value 1 . Heterogeneity among the included studies was assessed using graphical exploration of funnel plots, the Cochrane $Q$-statistic ( $p<0.1$ was considered representative of statistically significant heterogeneity) and the $I^{2}$ statistic $\left(I^{2}>\right.$ $50 \%$ was considered to represent substantial heterogeneity). In addition, sensitivity analysis on 5-year overall survival across six variables was conducted in order to investigate the robustness of the findings of this meta-analysis.

\section{Results}

\section{Research characteristics}

A preliminary search found 2180 related articles. After deleting duplicates, 1958 studies remained, of which 1923 were excluded based on the title or abstract. Finally, the full text of 35 articles was evaluated; 11 of these were further excluded. The reasons for exclusion were as follows: article content [23-26] $(n=4)$, no comparison study [27-30] $(n=5)$, non-English language $(n=1)$, and insufficient follow-up time $(n=1)$. A total of 24 articles were included in the study, including 5 randomised controlled trials [31-35], 16 retrospective studies [18, 19, 36-49], and 3 prospective studies [17, 50,51] (Fig. 1). The features of included studies are shown in Table 1. 
Fig. 1 Flowchart of document retrieval
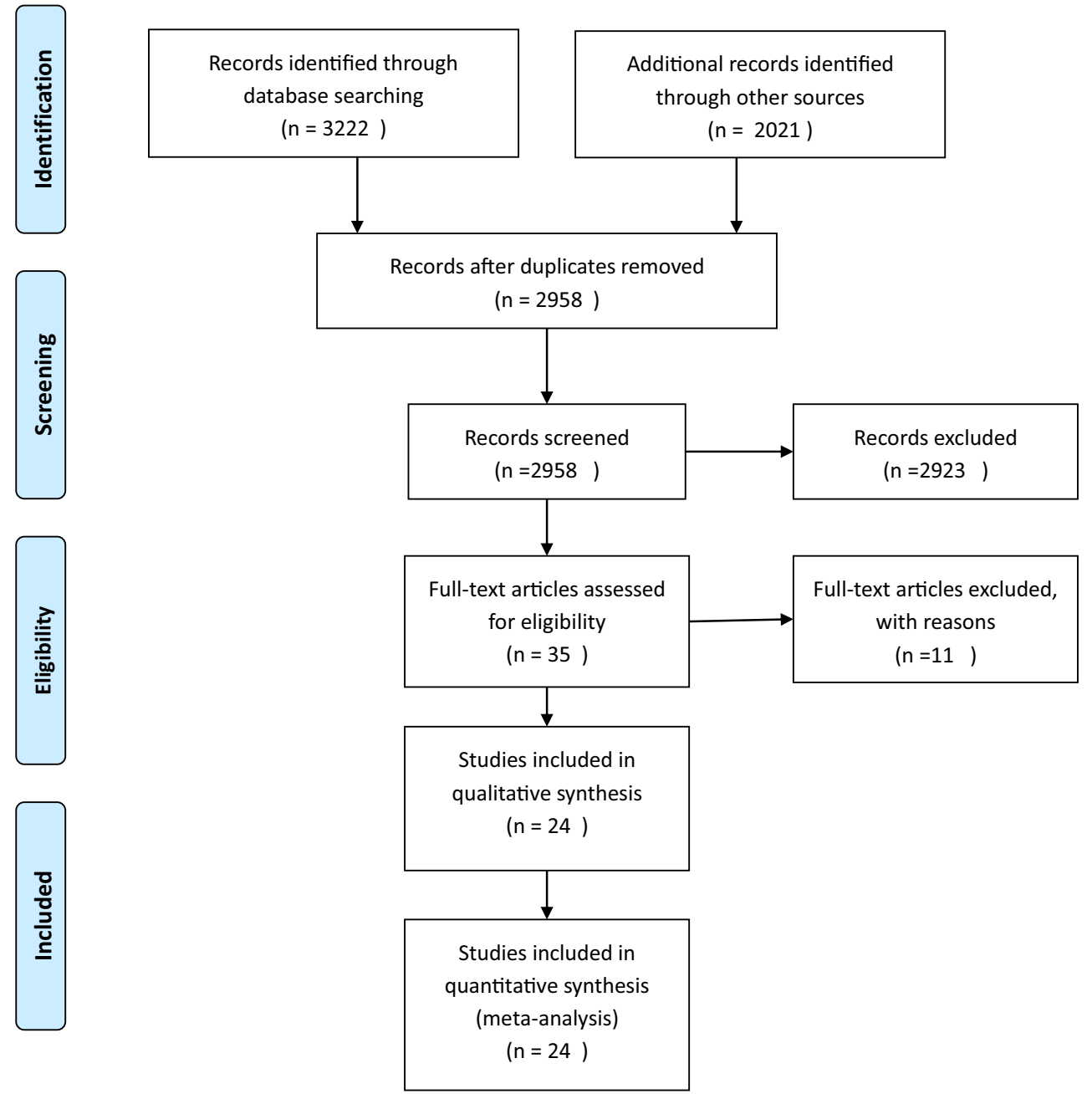

\section{Risk of bias and research quality}

The systematic review was carried out in accordance with the Cochrane Handbook [52]. For randomised controlled trials, Cochrane collaborative tools were used to assess risk of bias [50] (Fig. 2a). For prospective and retrospective cohort studies, we used the methodological index for non-randomized studies (MINORS) to assess bias [53]. The level of evidence was based on the National Health and Medical Research Council's classification[54]. According to the Cochrane Collaboration Tool, all included non-randomised controlled trials were judged to have a low risk of bias (Fig. 2b).

\section{Three-year survival rate}

In the 24 studies included, only Amelung et al. did not report overall survival rate [42], and the remaining 23 studies compared the 3-year survival rates between the stent as a bridge to surgery (SBTS) and emergency surgery groups. A total of 2365 patients were included in the studies. The results showed the survival rates of the two groups were $62.8 \%$ and $59.1 \%$ respectively ( $\mathrm{OR}=0.88,95 \% \mathrm{CI} 0.69-1.12)$. There was no significant difference between the two groups $(P=0.05$, $I^{2}=35 \%$ ) (Fig. 3). The funnel plot did not show the presence of significant deviations (Fig. 9a).

\section{Five-year survival rate}

The 5-year overall survival rates of the two groups were obtained. A total of 1426 patients were included in the studies. The results showed that the survival rates of the two groups were $62.6 \%$ and $57.2 \%$, respectively $(\mathrm{OR}=0.91,95 \% \mathrm{CI}$ $0.70-1.17, P=0.67)$. There was no statistically significant difference between the two groups $\left(P=0.67, I^{2}=0 \%\right.$, Fig. 4). The funnel plot showed no significant deviation (Fig. 9b).

\section{Three-year disease-free survival rate}

A total of 14 studies reported the 3-year disease-free survival rate, with a total of 1658 patients enrolled in the studies. The 3-year disease-free survival rates in the 


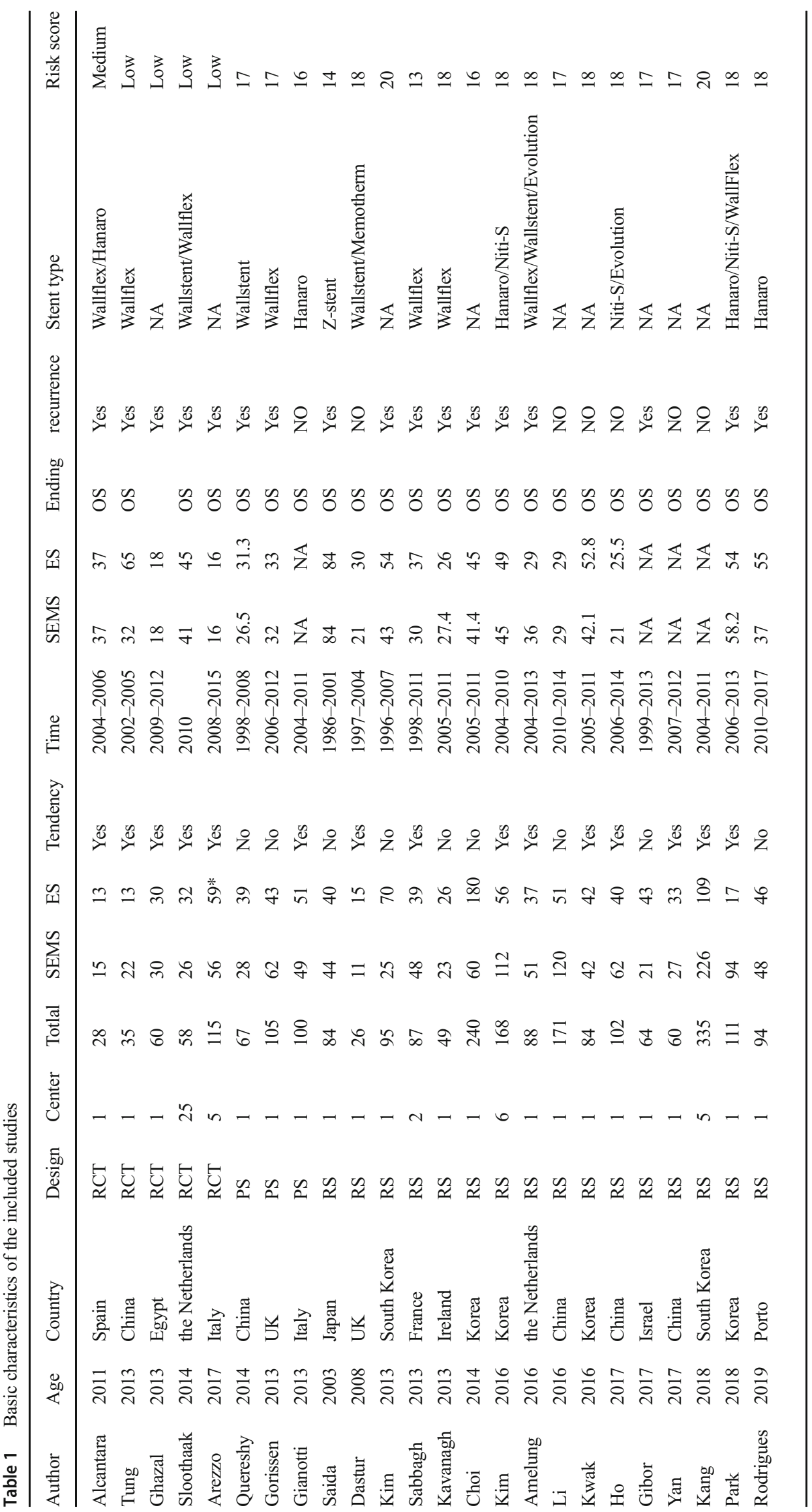


Fig. 2 a Risk of bias assessment of RCT included. b Quality studies included (using the ROBINS-I tool for assessment of risk of bias) assessment of non-randomised
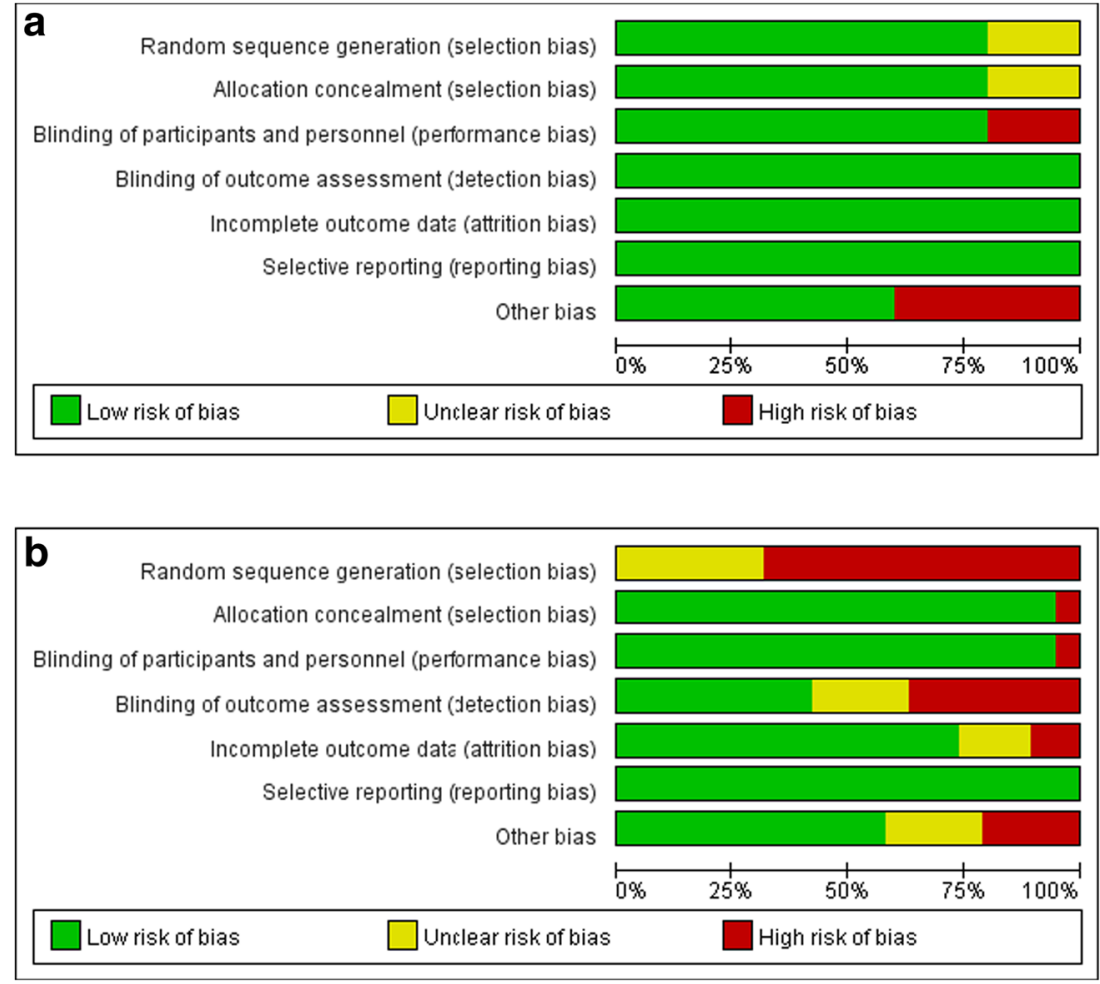

SEMS and emergency surgery groups were $59.6 \%$ and $58.8 \%$, respectively (OR $=1.14,95 \%$ CI $0.91-1.42)$. There was no significant difference between the two groups ( $P=0.65, I^{2}=36 \%$, Fig. 5), and the funnel plot did not show the presence of publication bias (Fig. 9c).

\section{Five-year disease-free survival rate}

Five-year disease-free survival was obtained from six studies, and a total of 1001 patients were included in the studies. The meta-analysis showed that the 5-year disease-free survival in

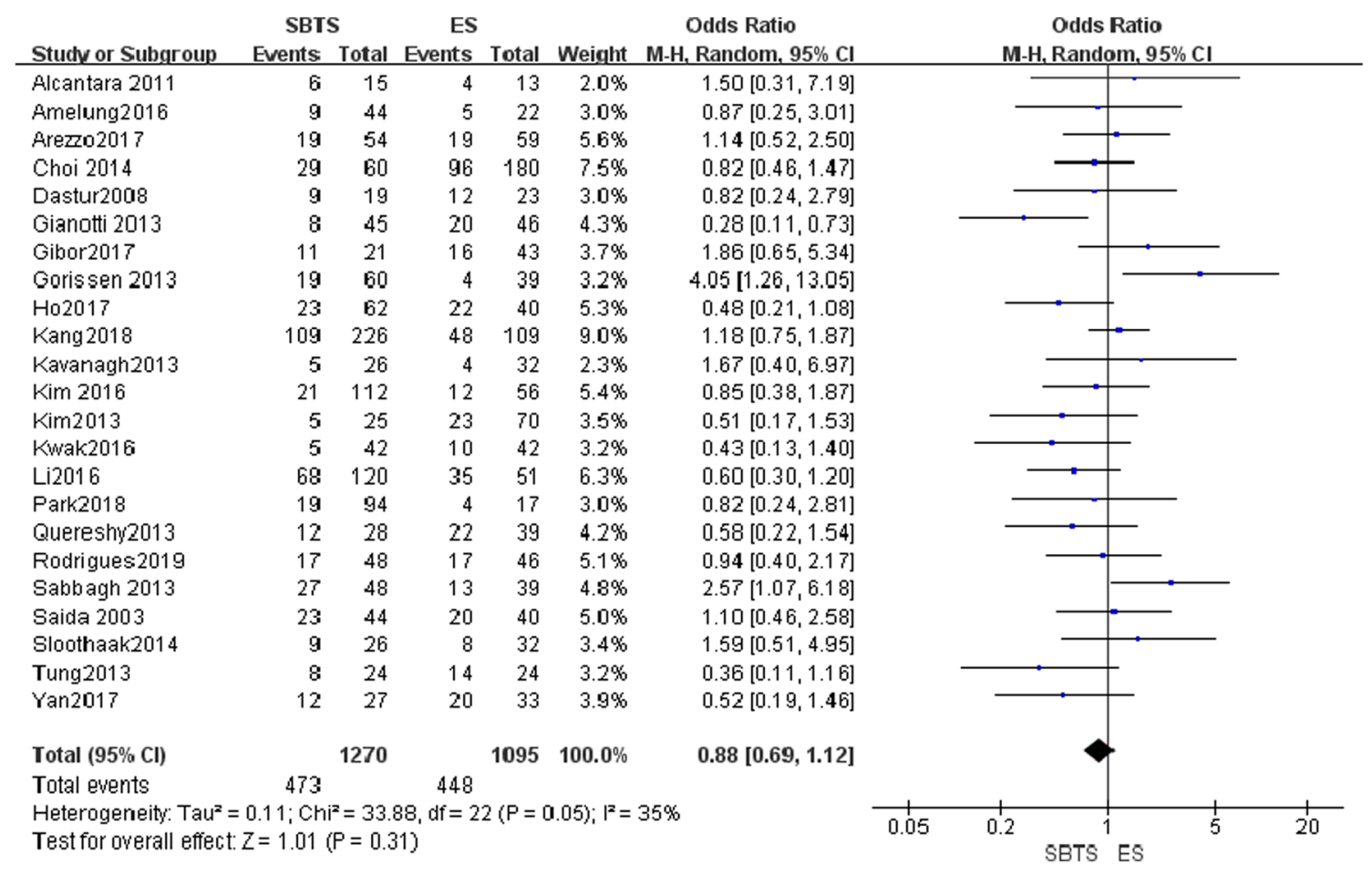

Fig. 3 Forest plot of 3-year OS between patients treated with SBTS or ES for MCO 


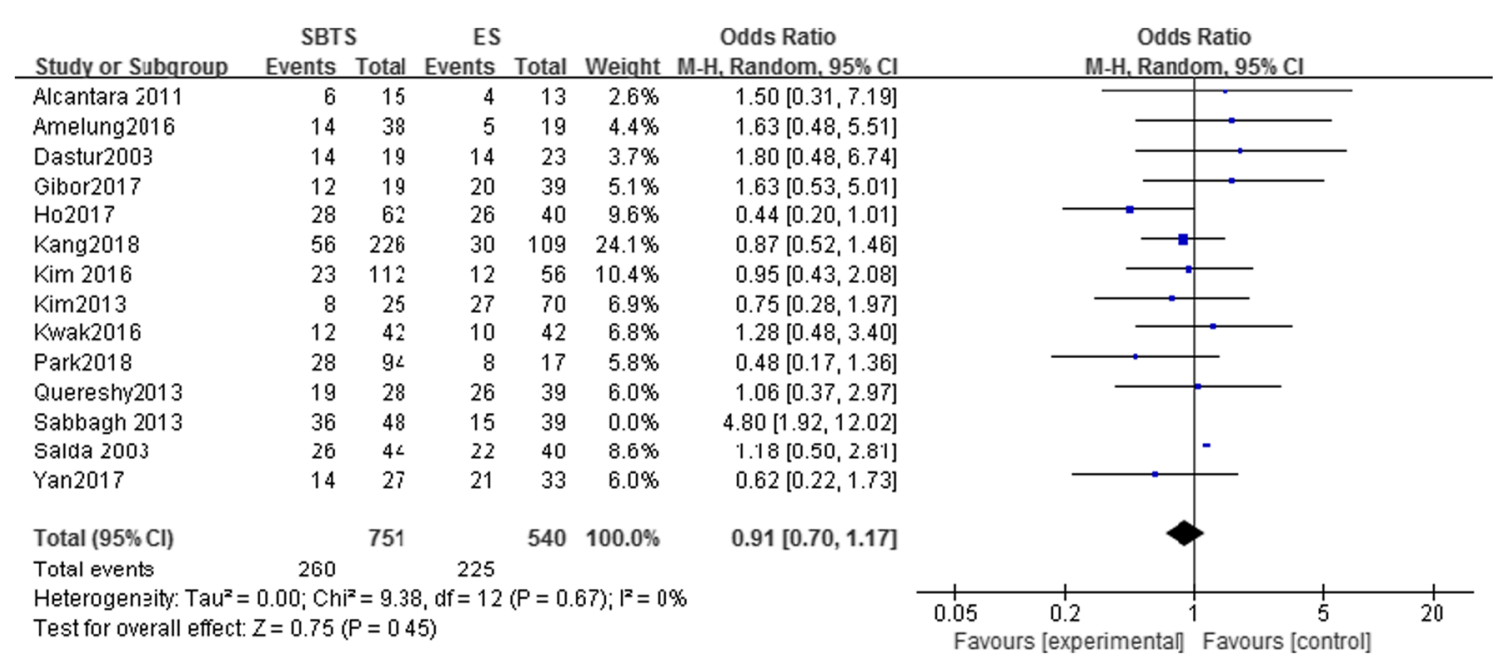

Fig. 4 Forest plot of 5-year OS between patients treated with SBTS or ES for MCO

the SEMS and emergency surgery groups was $43.7 \%$ and $44.0 \%$, respectively $(\mathrm{OR}=1.35,95 \%$ CI $0.91-2.02)$. There was no statistically significant difference between the two groups ( $P=0.17, I^{2}=0 \%$, Fig. 6). In addition, the funnel plot showed no significant deviation (Fig. 9d).

\section{Local recurrence}

The local recurrence rate in the SEMS and emergency surgery groups was $8.8 \%$ and $5.7 \%$, respectively $(\mathrm{OR}=1.37,95 \% \mathrm{CI}$ 0.84-2.23), with no significant difference between the two groups $\left(P=0.92, I^{2}=0 \%\right.$, Fig. 7). The funnel plot did not show the existence of a publication bias (Fig. 9f).

\section{Overall recurrence}

A total of 17 studies on recurrence rates, including 13 cases of local recurrence, were included in this meta-analysis. The results showed an overall recurrence rate of $28.7 \%$ and $27.5 \%$ for the SBTS and emergency surgery groups, respectively $(\mathrm{OR}=1.04,95 \% \mathrm{CI} 0.77-1.41)$. There was no significant difference between the two groups $\left(P=0.14, I^{2}=28 \%\right)$ (Fig. 8). The funnel plot did not show the existence of publication bias (Fig. 9e).

\section{Sensitivity analysis}

With regard to the 5-year survival rate, sensitivity analyses were performed on 6 different variables included in 15 studies, including study type, study area, total number of patients, number of patients receiving stents, technical success rate, and publication year (Table 2).

Subgroup analysis of 2 randomised studies showed low heterogeneity, and there was no significant decrease in survival in the SEMS group $(\mathrm{OR}=0.66,95 \% \mathrm{CI} 0.16-2.67, P=$
$0.56,39$ vs. 37 ); these results were contrary to nonrandomised studies with a high degree of heterogeneity (OR $=0.88,95 \%$ CI $0.65-1.19, P=0.4,781$ vs. 562).

Subgroup analysis of the study region between Europe and Asia showed a similar result in the 5-year survival rate $(\mathrm{OR}=$ $0.76,95 \%$ CI $0.58-1.0, P=0.05,684$ vs. 470 ; and $\mathrm{OR}=1.61$, 95\% CI $0.94-2.74, P=0.08,136$ vs. 129$)$, with low heterogeneity $\left(I^{2}=26 \%, P=0.28\right)$.

For the year of publication, a subgroup analysis showed that the heterogeneity was low between years after 2015 and before, studies after $2015(\mathrm{OR}=0.85,95 \%$ CI $0.61-1.19, P=$ $0.34,628$ vs. 326), studies before 2015 (OR $=0.86,95 \% \mathrm{CI}$ $0.48-1.52, P=0.60,192$ vs. 237$)$; there was no significant difference in the 5-year survival rate between the two subgroups.

The subgroup analysis for the total number of patients $(\geq$ 70 and $<70)$ and the number of patients receiving stents $(\geq 30$ and $<30$ ) revealed that all studies showed low heterogeneity and similar results for 5-year overall survival.

When assessing the potential impact of SEMS surgery, studies with a success rate of $\geq 90 \%$ had a higher heterogeneity, but had a significant survival benefit (OR 0.65, 95\% CI $0.45-0.94, P=0.02,424$ vs. 262).

\section{Discussion}

The current systematic review and meta-analysis showed that the use of SEMS as a surgical transition in malignant obstructions caused by colorectal cancer might not lead to a negative impact on the long-term prognosis of the tumour compared with ES. The prognosis was similar between the two groups in 3-year and 5-year survival rates, and there were no significant differences in local or systemic recurrence. 


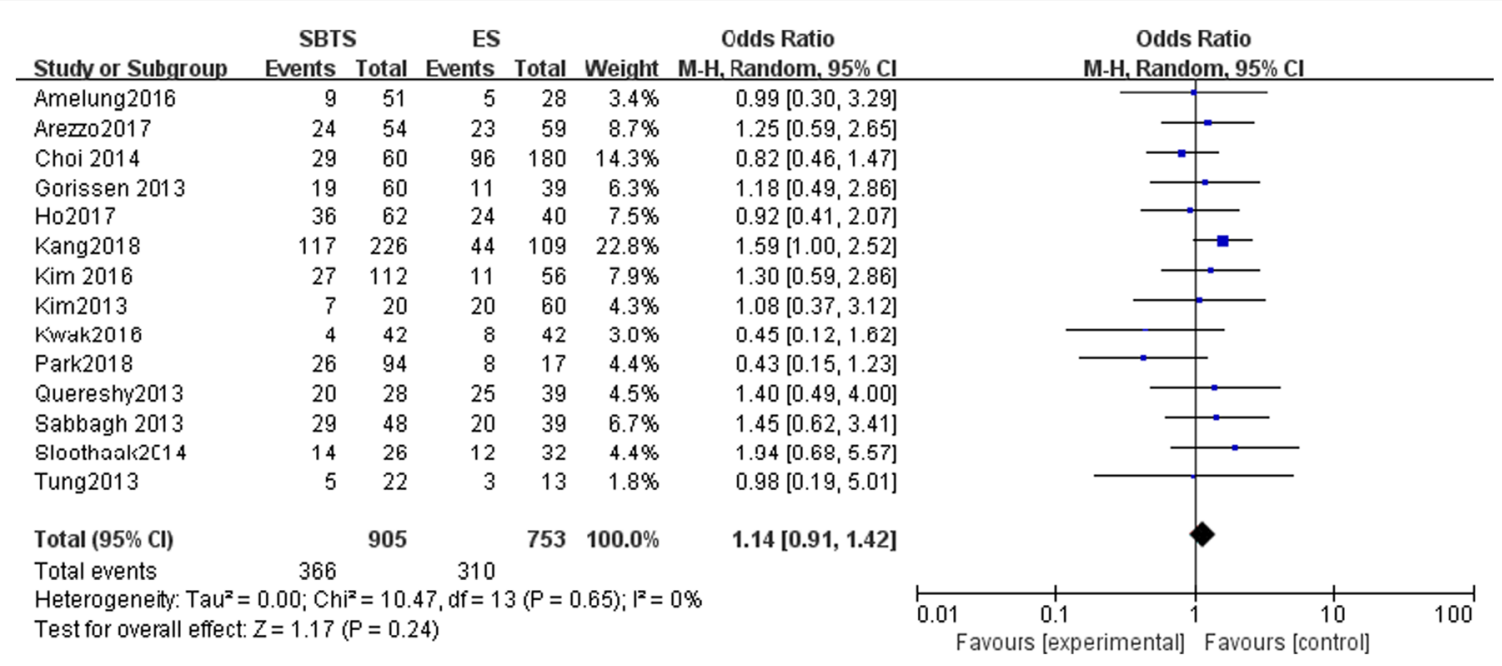

Fig. 5 Forest plot of 3-year DFS between patients treated with SBTS or ES for MCO

Patients with colorectal cancer complicated with acute intestinal obstruction were usually in a poor general condition and might have various problems such as dehydration, anaemia, metabolic disorders, malnutrition, and acidbase imbalance. The use of SEMS as a transition to surgery can alleviate these acute risks. Converting emergency surgery to elective surgery resulted in a more meticulous evaluation and treatment, as shown by the better shortterm results [55]. At the same time, however, stent mechanical stress might cause long-term effects on tumour cell spreading; therefore, the debate on BTS persists [15, $19,24,34,35,56]$. Related studies have shown that mechanical friction of the colonoscope and guidewire, mechanical expansion after stent release, and stent-related perforation during stenting can lead to the localised spreading of tumour cells and dissemination through blood and lymphatic vessels $[57,58]$. Sterne et al. found that the expression of cytokeratin 20 was significantly increased in peripheral venous blood after stent implantation [59], and Maruthachalam et al. demonstrated that the circulating levels of CEA and CK20 mRNA were significantly increased after colon stenting [15]; Higgins-Julian and Kim et al. found that the invasion rate of nerves and lymph nodes increased after implantation of SEMS, but no difference in survival rate was found compared with emergency surgery. Moreover, no studies have demonstrated a relationship between stent placement and tumour recurrence. In addition, the oncological significance of these pathological results remains unclear [18, 21]. Gorissen et al. showed that patients with BTS had an increased local recurrence rate, especially in younger subjects; however, in multivariate analysis, stent placement was not associated with an increase in local recurrence rate and had no effect on overall survival [17]; Cao et al. found that in perforations caused by colonic stenting, there was no significant increase in abdominal or distant metastasis during long-term follow-up. A phase III clinical trial conducted by Gietelink et al. confirmed that there was no significant correlation between the presence of circulating tumour cells in the blood of patients with colorectal cancer and decreased survival [60]. Although evidence has shown that tumour cells can spread or metastasise during stent implantation, the current systematic review shows that BTS has no negative effects on long-term survival and prognosis. However, we still needed further relevant clinical trials to verify this conclusion.

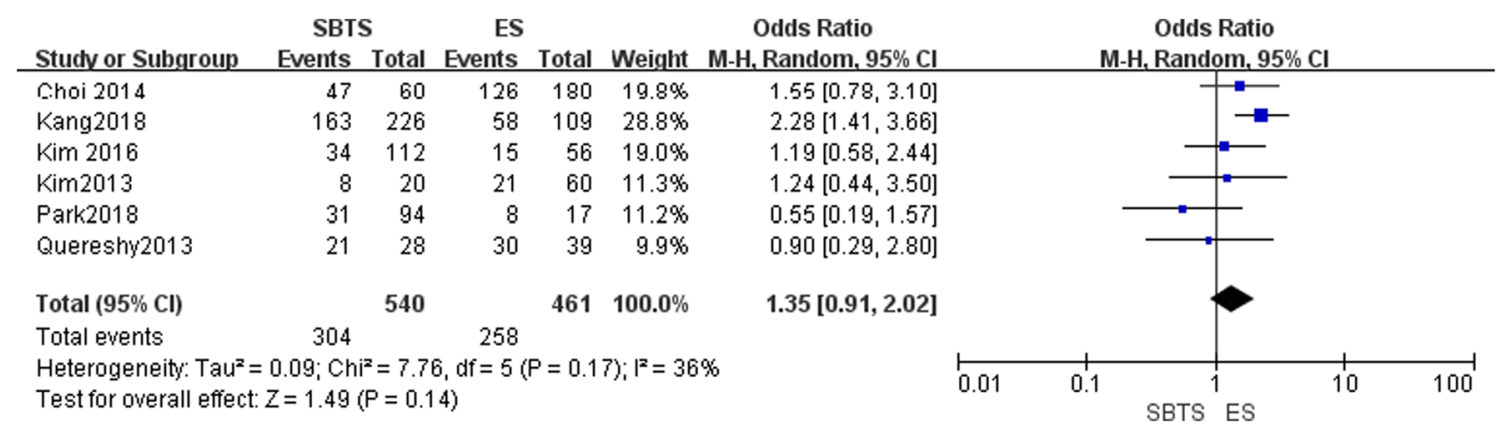

Fig. 6 Forest plot of 5-year DFS between patients treated with SBTS or ES for MCO 


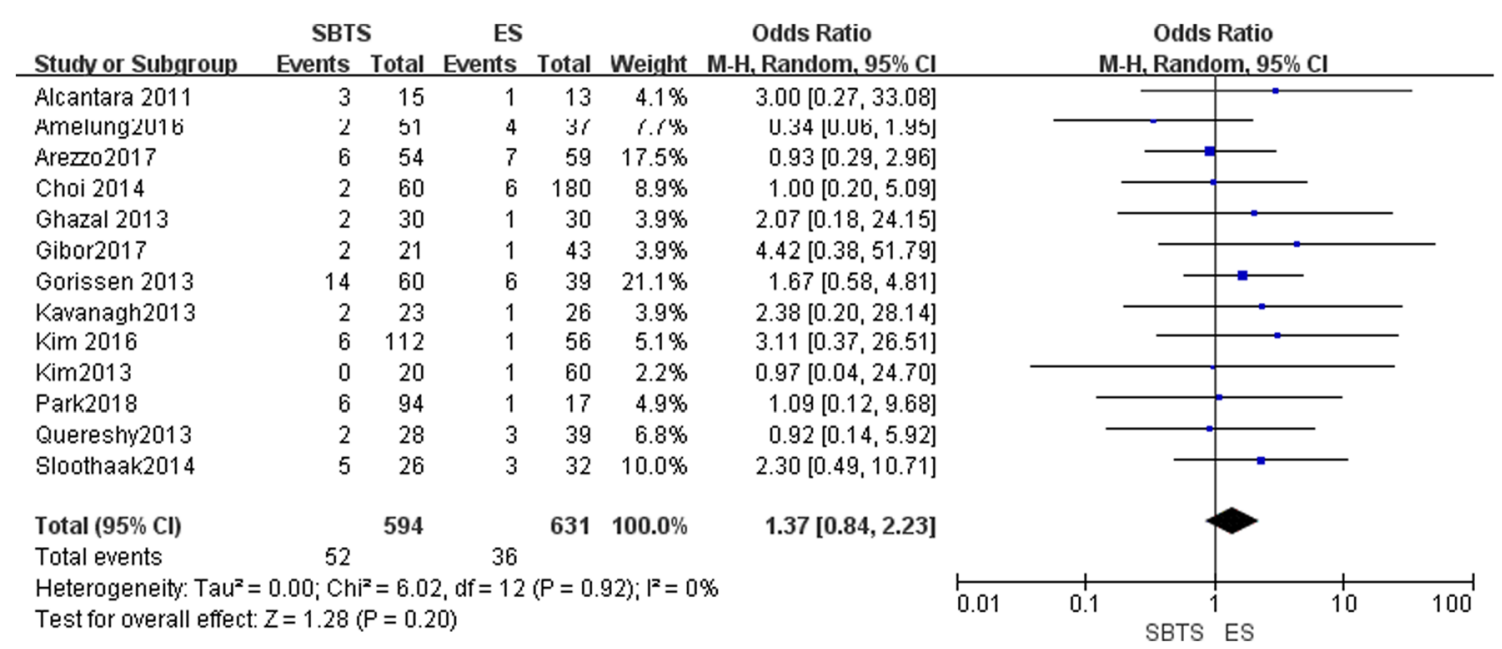

Fig. 7 Meta-analysis of local recurrences between patients treated with SBTS versus ES for MCO

Ceresoli et al. compared long-term oncologic outcomes of SBTS and ES in malignant left-sided colonic obstructions, and they thought there were no significant differences reported in local and overall recurrence rates [61]. Amelung et al. compared procedure-related mortality and morbidity rates between primary resection and stent placement as a bridge to surgery followed by elective resection for patients with acute right-sided colonic obstruction (RSCO), and they thought primary resection for patients with acute RSCO seems to be associated with higher mortality and major morbidity rates than stent placement and elective resection [62]. Other meta-analyses compared the long-term outcomes of stents as BTS and emergency sur- gery and found that BTS was oncologically comparable with emergency surgery with respect to OS, DFS, and recurrence, and there was no difference in long-term tumour outcomes [22, 63-66]. The results of 24 studies included in our systematic review also confirmed previous findings, and although the number of studies had increased, more randomised studies are still recommended to draw a better conclusion in this topic.

Artinyan et al. believe that postoperative complications of SEMS might have a negative impact on long-term oncologic outcomes and survival rates [67]. The most common complications of colon stenting were perforation, displacement, and re-obstruction. Perforation was the

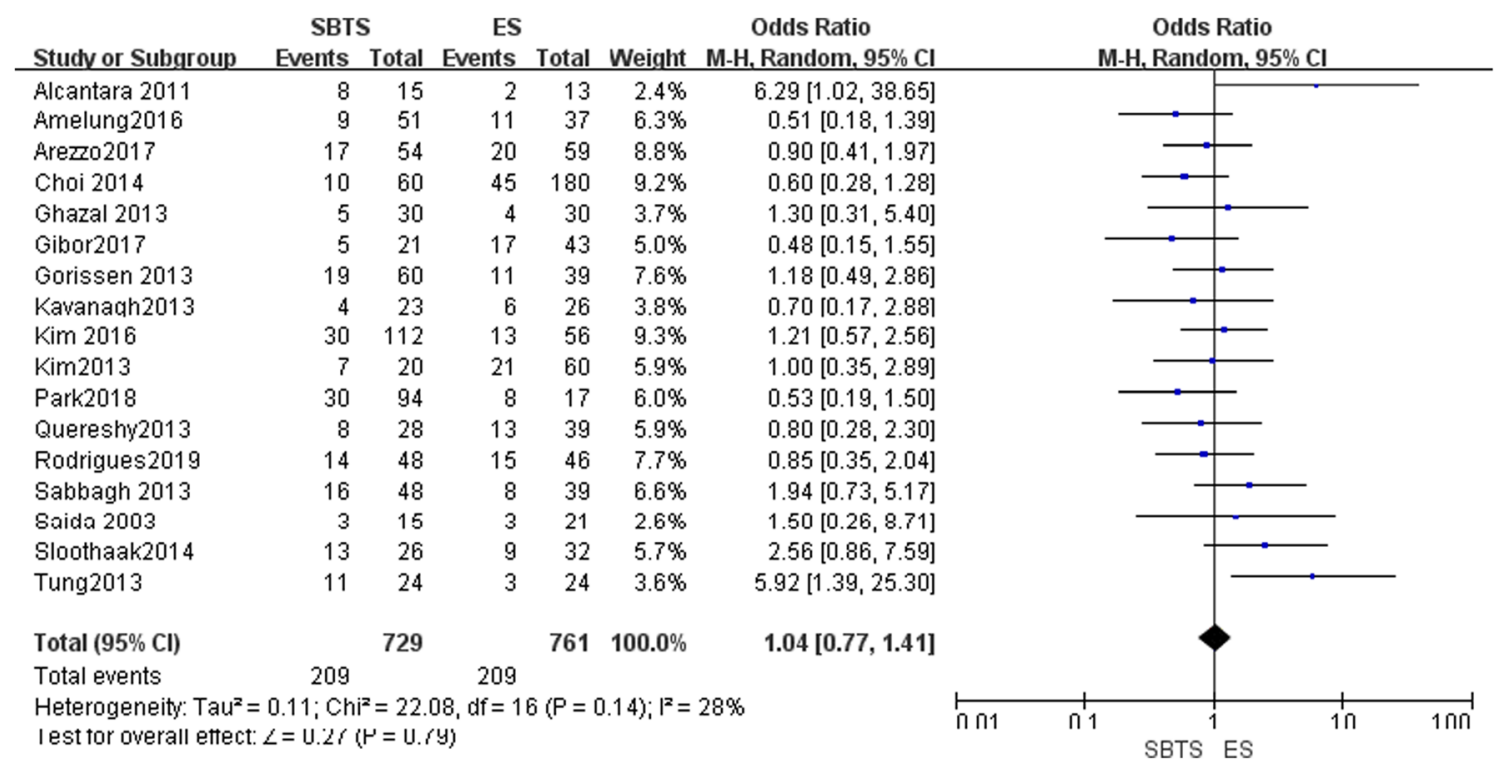

Fig. 8 Meta-analysis of overall recurrences between patients treated with SBTS versus ES for MCO 

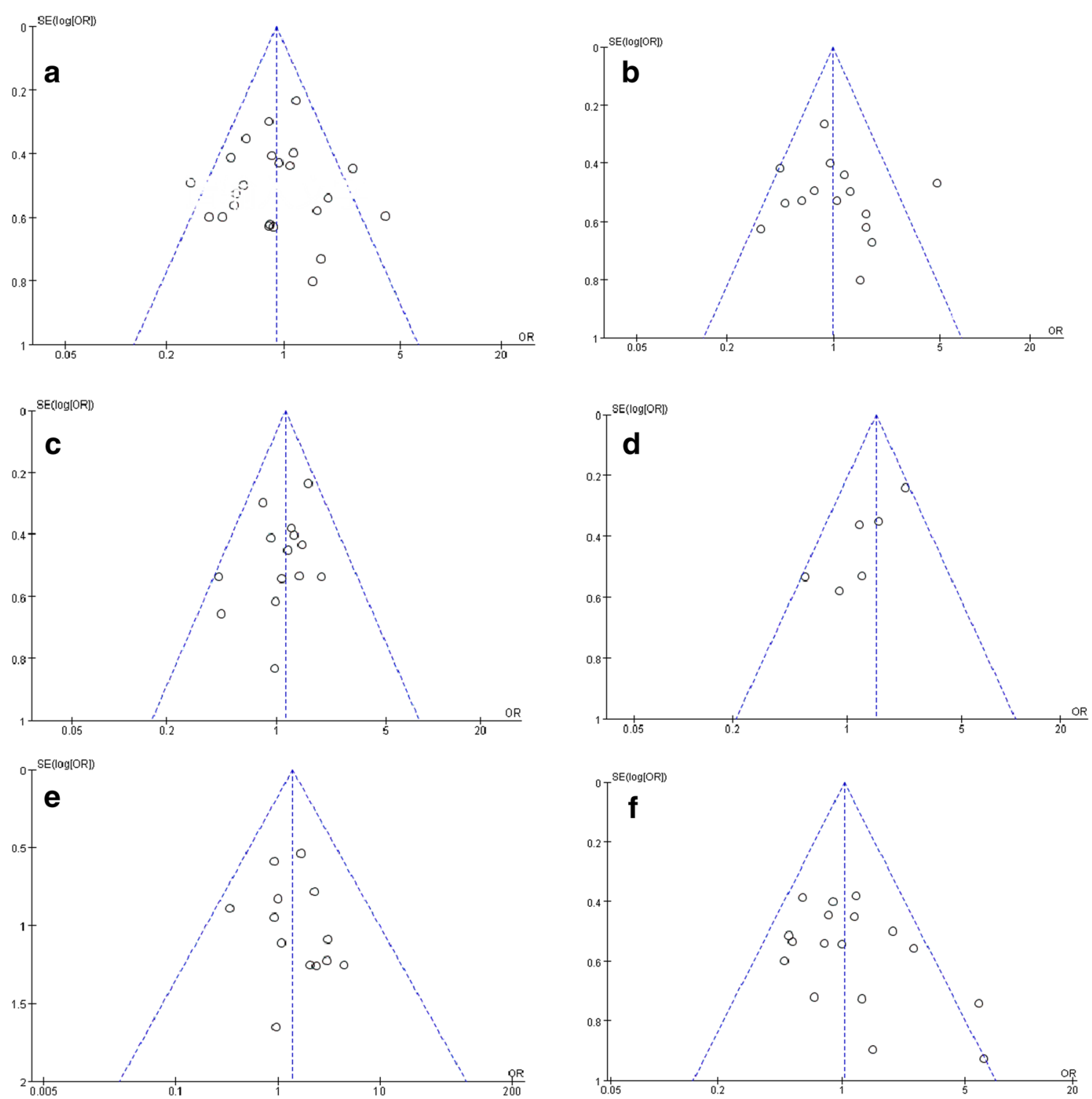

Fig. 9 Funnel plots were plotted of all studies that reported on 3-year overall survival (a), 5-year overall survival (b), 3-year DFS (c), 5-year DFS (d), local recurrences $(\mathbf{e})$, and overall recurrences (f)

most life-threatening complication, with a reported incidence of $0-16 \%$ [68-70]; Higgins and Kwakn suggested that an increase in perforation rate might increase local recurrence rates and consequently affect long-term survival outcomes $[43,52]$. In fact, stent-related perforation may be decreased to a very low extent. Avoiding adjuvant bevacizumab treatment or balloon dilatation during stent implantation might significantly reduce stent-related perforation [32]; in addition, the skills of endoscopists also have an important role in preventing stent perforation. Bridoux et al. and ESGE guidelines recommend that at least 20 cases are treated to overcome the learning curve.
This meta-analysis provides a contribution to highlight the alternative role of SEMS, since previously published metaanalyses did not focus on the long-term oncological effects of SEMS. We included more studies than the previous reviews or meta-analyses, with a corresponding sample size increase, and now the stratification of stenting success rate showed a different result from previous reviews. However, there were still limitations due to the shortage of studies on long-term tumour outcomes, especially randomised studies. Different choices of surgical procedures in emergency surgery (e.g. routine intraoperative lavage decompression vs. preventive ostomy) might also limit the reach of the conclusions. 
Table 2 Sensitivity analysis of 5-year survival rate between SBTS and ES groups

\begin{tabular}{|c|c|c|c|c|c|c|c|c|}
\hline Variable & Subgroup & Number & Number of cases & OR & $95 \% \mathrm{CI}$ & $P$ & Heterogeneity $P$ & $I^{2}$ \\
\hline \multirow[t]{2}{*}{ Years } & $\geq 2015$ & 8 & 1000 & 0.85 & $0.61-1.19$ & 0.34 & 0.33 & $13 \%$ \\
\hline & $<2015$ & 7 & 429 & 0.86 & $0.48-1.52$ & 0.6 & 0.10 & $44 \%$ \\
\hline \multirow[t]{2}{*}{ Area } & Asia & 10 & 1154 & 0.76 & $0.58-1.0$ & 0.05 & 0.41 & $4 \%$ \\
\hline & Europe & 5 & 265 & 1.61 & $0.94-2.74$ & 0.08 & 0.46 & $0 \%$ \\
\hline \multirow[t]{2}{*}{ Type of study } & $\mathrm{RCT}$ & 2 & 76 & 0.66 & $0.16-2.67$ & 0.56 & 0.15 & $52 \%$ \\
\hline & Non-RCT & 13 & 498 & 0.88 & $0.65-1.19$ & 0.4 & 0.19 & $25 \%$ \\
\hline \multirow[t]{2}{*}{ Total number of patients } & $\geq 70$ & 9 & 1132 & 0.91 & $0.64-1.3$ & 0.56 & 0.16 & $32 \%$ \\
\hline & $<70$ & 6 & 287 & 0.72 & $0.42-1.24$ & 0.24 & 0.3 & $17 \%$ \\
\hline \multirow[t]{2}{*}{ Number of SEMS } & $\geq 30$ & 8 & 955 & 1.07 & $0.77-1.47$ & 0.69 & 0.37 & $8 \%$ \\
\hline & $<30$ & 7 & 464 & 0.64 & $0.42-0.98$ & 0.04 & 0.34 & $12 \%$ \\
\hline \multirow[t]{2}{*}{ SEMS success rate } & $\geq 95 \%$ & 7 & 686 & 0.65 & $0.45-0.94$ & 0.02 & 0.88 & $0 \%$ \\
\hline & $<95 \%$ & 5 & 350 & 1.21 & $0.56-2.27$ & 0.54 & 0.15 & $41 \%$ \\
\hline
\end{tabular}

\section{Conclusion}

The results of this meta-analysis suggest the long-term oncological outcome of SEMS placement and second stage surgery is comparable with that of emergency surgery. High success rate of stent implantation might lead to better outcomes. An alternative role of BTS was reinforced by this analysis and a higher technical success rate is important in clinical practice quality control. We also believe that there will be more relevant studies to confirm our conclusions, which will benefit more patients.

Author contributions Yinghao Cao, Junnan Gu, Shenghe Deng, Jiang Li, $\mathrm{Ke} \mathrm{Wu}$, and Kailin Cai meet all the criteria for the definition of authorship and contributed substantially to the manuscript. Yinghao Cao, Junnan Gu, and Shenghe Deng contributed equally to this work and they were considered co-first authors. Ke Wu and Kailin Cai are the correspondent authors.

Funding information This study was financially supported by grants from the Science and Technology Department of Hubei Province (no. 2018CFC884), the Wu Jieping Medical Foundation of China (no.320.2710.1843), and the Clinical Research Physician Program of Tongji Medical College, HUST.

\section{Compliance with ethical standards}

This study was approved by the Ethics Committee of the Tongji Medical College, Huazhong University of Science and Technology

Conflict of interest The authors declare that they have no conflict of interest.

Open Access This article is distributed under the terms of the Creative Commons Attribution 4.0 International License (http:// creativecommons.org/licenses/by/4.0/), which permits unrestricted use, distribution, and reproduction in any medium, provided you give appropriate credit to the original author(s) and the source, provide a link to the Creative Commons license, and indicate if changes were made.

\section{References}

1. Bray F, Ferlay J, Soerjomataram I, Siegel RL, Torre LA, Jemal A (2018) Global cancer statistics 2018: GLOBOCAN estimates of incidence and mortality worldwide for 36 cancers in 185 countries. CA Cancer J Clin 68:394-424

2. Ahn HJ, Kim SW, Lee SW, Lee SW, Lim C, Kim JS, Cho YK, Park JM, Lee IS, Choi M (2016) Long-term outcomes of palliation for unresectable colorectal cancer obstruction in patients with good performance status: endoscopic stent versus surgery. Surg Endosc 30:4765-4775

3. Lee HJ, Hong SP, Cheon JH, Kim TI, Min BS, Kim NK, Kim WH (2011) Long-term outcome of palliative therapy for malignant colorectal obstruction in patients with unresectable metastatic colorectal cancers: endoscopic stenting versus surgery. Gastrointest Endosc 73:535-542

4. Sebastian S, Johnston S, Geoghegan T, Torreggiani W, Buckley M (2004) Pooled analysis of the efficacy and safety of self-expanding metal stenting in malignant colorectal obstruction. Am J Gastroenterol 99:2051-2057

5. Ahn HJ, Kim SW, Lee SW, Lee SW, Lim CH, Kim JS, Cho YK, Park JM, Lee IS, Choi MG (2016) Long-term outcomes of palliation for unresectable colorectal cancer obstruction in patients with good performance status: endoscopic stent versus surgery. Surg Endosc Other Interv Tech 30:4765-4775

6. Atukorale YN, Church JL, Hoggan BL, Lambert RS, Gurgacz SL, Goodall S, Maddern GJ (2016) Self-expanding metallic stents for the management of emergency malignant large bowel obstruction: a systematic review. J Gastrointest Surg 20:455-462

7. Vitale MA, Villotti G, D'Alba L, Frontespezi S, Iacopini F, Iacopini G (2006) Preoperative colonoscopy after self-expandable metallic stent placement in patients with acute neoplastic colon obstruction. Gastrointest Endosc 63:814-819

8. Tanis PJ, Paulino PN, van Hooft JE, Consten EC, Bemelman WA (2015) Resection of obstructive left-sided colon cancer at a national level: a prospective analysis of short-term outcomes in 1,816 patients. Dig Surg 32:317-324

9. Dohmoto M (1991) New method: endoscopic implantation of rectal stent in palliative treatment of malignant stenosis. Endoscopia Digestiva:1507-1512

10. Tejero E, Mainar A, Fernandez L, Tobio R, De Gregorio MA (1994) New procedure for the treatment of colorectal neoplastic obstructions. Dis Colon Rectum 37:1158-1159 
11. van Hooft JE, Fockens P, Marinelli AW, Timmer R, van Berkel AM, Bossuyt PM, Bemelman WA (2008) Early closure of a multicenter randomized clinical trial of endoscopic stenting versus surgery for stage IV left-sided colorectal cancer. ENDOSCOPY 40: 184-191

12. Sahebally SM, Sarwar A, Cooke F (2014) Short-term outcomes following the use of self-expanding metallic stents in acute malignant colonic obstruction-a single centre experience. Int J Surg 12: 1198-1202

13. Arezzo A, Passera R, Lo SG, Verra M, Bonino MA, Targarona E, Morino M (2017) Stent as bridge to surgery for left-sided malignant colonic obstruction reduces adverse events and stoma rate compared with emergency surgery: results of a systematic review and meta-analysis of randomized controlled trials. Gastrointest Endosc $86: 416-426$

14. Matsuda A, Yamada T, Matsumoto S, Sakurazawa N, Kawano Y, Sekiguchi K, Matsutani T, Miyashita M, Yoshida H (2019) Shortterm outcomes of a self-expandable metallic stent as a bridge to surgery vs. a transanal decompression tube for malignant largebowel obstruction: a meta-analysis. Surg Today

15. Maruthachalam K, Lash GE, Shenton BK, Horgan AF (2007) Tumour cell dissemination following endoscopic stent insertion. Br J Surg 94:1151-1154

16. Kim JS, Hur H, Min BS, Sohn SK, Cho CH, Kim NK (2009) Oncologic outcomes of self-expanding metallic stent insertion as a bridge to surgery in the management of left-sided colon cancer obstruction: comparison with nonobstructing elective surgery. World J Surg 33:1281-1286

17. Gorissen KJ, Tuynman JB, Fryer E, Wang L, Uberoi R, Jones OM, Cunningham C, Lindsey I (2013) Local recurrence after stenting for obstructing left-sided colonic cancer. Br J Surg 100:1805-1809

18. Kim HJ, Choi GS, Park JS, Park SY, Jun SH (2013) Higher rate of perineural invasion in stent-laparoscopic approach in comparison to emergent open resection for obstructing left-sided colon cancer. Int J Color Dis 28:407-414

19. Sabbagh C, Browet F, Diouf M, Cosse C, Brehant O, Bartoli E, Mauvais F, Chauffert B, Dupas JL, Nguyen-Khac E, Regimbeau JM (2013) Is stenting as "a bridge to surgery" an oncologically safe strategy for the management of acute, left-sided, malignant, colonic obstruction? A comparative study with a propensity score analysis. Ann Surg 258:107-115

20. Thorlacius H (2008) Tumour cell dissemination following endoscopic stent insertion (Br J Surg 2007; 94: 1151-1154). Br J Surg 95:127-128 author reply 128

21. Higgins JP, Altman DG, Gotzsche PC, Juni P, Moher D, Oxman AD, Savovic J, Schulz KF, Weeks L, Sterne JA (2011) The Cochrane Collaboration's tool for assessing risk of bias in randomised trials. BMJ 343:d5928

22. Amelung FJ, Burghgraef TA, Tanis PJ, van Hooft JE, ter Borg F, Siersema PD, Bemelman WA, Consten ECJ (2018) Critical appraisal of oncological safety of stent as bridge to surgery in left-sided obstructing colon cancer; a systematic review and meta-analysis. Crit Rev Oncol Hematol 131:66-75

23. Di Saverio S, Birindelli A, Segalini E, Novello M, Larocca A, Ferrara F, Binda GA, Bassi M (2018) "To stent or not to stent?": immediate emergency surgery with laparoscopic radical colectomy with CME and primary anastomosis is feasible for obstructing left colon carcinoma. Surg Endosc 32:2151-2155

24. Matsuda A, Miyashita M, Matsumoto S, Sakurazawa N, Kawano Y, Yamahatsu K, Sekiguchi K, Yamada M, Hatori T, Yoshida H (2018) Colonic stent-induced mechanical compression may suppress cancer cell proliferation in malignant large bowel obstruction. Surg Endosc

25. Tomita M, Saito S, Makimoto S, Yoshida S, Isayama H, Yamada T, Matsuzawa T, Enomoto T, Kyo R, Kuwai T, Hirata N, Shimada M, Hirakawa T, Koizumi K, Saida Y (2019) Self-expandable metallic stenting as a bridge to surgery for malignant colorectal obstruction: pooled analysis of 426 patients from two prospective multicenter series. Surg Endosc 33:499-509

26. Xiong X, Xu L, Fan L, Cheng D, Zheng B (2019) Long-term follow-up of self-expandable metallic stents in benign tracheobronchial stenosis: a retrospective study. BMC Pulm Med 19:33

27. Imai M, Kamimura K, Takahashi Y, Sato T, Isokawa O, Maruyama M, Kobayashi T, Hayashi K, Terai S (2018) The factors influencing long-term outcomes of stenting for malignant colorectal obstruction in elderly group in community medicine. Int J Color Dis 33:189197

28. Donlon NE, Kelly ME, Narouz F, McCormick PH, Larkin JO, Mehigan BJ (2019) Colonic stenting as a bridge to surgery in malignant large bowel obstruction: oncological outcomes. Int J Color Dis 34:613-619

29. Berselli M, Borroni G, Livraghi L, Quintodei V, Sambucci D, Cortelezzi C, Segato S, Carcano G, Cocozza E (2019) Laparoscopic approach to large bowel neoplastic obstruction after self-expandable-metal-stent (SEMS) placement. Surg Laparosc Endosc Percutan Tech 29:133-137

30. Young CJ, Suen MK, Young J, Solomon MJ (2011) Stenting large bowel obstruction avoids a stoma: consecutive series of 100 patients. Color Dis 13:1138-1141

31. Alcantara M, Serra-Aracil X, Falco J, Mora L, Bombardo J, Navarro S (2011) Prospective, controlled, randomized study of intraoperative colonic lavage versus stent placement in obstructive left-sided colonic cancer. World J Surg 35:1904-1910

32. Ghazal AH, El-Shazly WG, Bessa SS, El-Riwini MT, Hussein AM (2013) Colonic endolumenal stenting devices and elective surgery versus emergency subtotal/total colectomy in the management of malignant obstructed left colon carcinoma. J Gastrointest Surg 17: $1123-1129$

33. Tung KL, Cheung HY, Ng LW, Chung CC, Li MK (2013) Endolaparoscopic approach versus conventional open surgery in the treatment of obstructing left-sided colon cancer: long-term followup of a randomized trial. Asian J Endosc Surg 6:78-81

34. Sloothaak DA, van den Berg MW, Dijkgraaf MG, Fockens P, Tanis PJ, van Hooft JE, Bemelman WA (2014) Oncological outcome of malignant colonic obstruction in the Dutch Stent-In 2 trial. Br J Surg 101:1751-1757

35. Arezzo A, Bini R, Lo SG, Verra M, Passera R (2017) The role of stents in the management of colorectal complications: a systematic review. Surg Endosc Other Interv Tech 31:2720-2730

36. Kang SI, Oh H, Yoo JS, Ahn S, Kim MH, Kim MJ, Son IT, Kim D, Kang S, Park YS, Yoon CJ, Shin R, Heo SC, Lee IT, Youk EG, Kim MJ, Chang TY, Park S, Sohn DK, Oh JH, Park JW, Ryoo S, Jeong S, Park KJ (2018) Oncologic outcomes of preoperative stent insertion first versus immediate surgery for obstructing left-sided colorectal cancer. Surg Oncol 27:216-224

37. Park J, Lee HJ, Park SJ, Hur H, Min BS, Cheon JH, Kim TI, Kim NK, Kim WH (2018) Long-term outcomes after stenting as a bridge to surgery in patients with obstructing left-sided colorectal cancer. Int J Color Dis 33:799-807

38. Yan F, Lou Z, Liu X, Wang Z, Xu X, Gao Y, He J, Wang H, Fu C, Zhang W, He H, Cai B, Yu E (2017) Long-term oncological outcomes of endoscopic stenting as a bridge to surgery versus emergency surgery for malignant colorectal obstruction: a comparative study. J Laparoendosc Adv Surg Tech 27:611-617

39. Ho K, Chan K, Kwok S, Lau PY (2017) Colonic self-expanding metal stent (SEMS) as a bridge to surgery in left-sided malignant colonic obstruction: an 8-year review. Surg Endosc 31:2255-2262

40. Gibor U, Perry Z, Tirosh D, Netz U, Rosental A, Fich A, Man S, Ariad S, Kirshtein B (2017) Comparison of the long-term oncological outcomes of stent as a bridge to surgery and surgery alone in malignant colonic obstruction. Israel Med Assoc J 19:736-740 
41. Kim MK, Kye BH, Lee IK, Oh ST, Ahn CH, Lee YS, Lee SC, Kang WK (2017) Outcome of bridge to surgery stenting for obstructive left colon cancer. ANZ J Surg

42. Amelung FJ, ter Borg F, Consten ECJ, Siersema PD, Draaisma WA (2016) Deviating colostomy construction versus stent placement as bridge to surgery for malignant left-sided colonic obstruction. Surg Endosc 30:5345-5355

43. Kwak MS, Kim WS, Lee J, Yang D, Yoon YS, Yu CS, Kim JC, Byeon J (2016) Does stenting as a bridge to surgery in left-sided colorectal cancer obstruction really worsen oncological outcomes? Dis Colon Rectum 59:725-732

44. Li Z, Wu X, Wu H, Chang W, Chang X, Yi T, Shi Q, Chen J, Feng Q, Zhu D, Wei Y, Zhong Y, Xu J (2016) Self-expandable metallic stent as a bridge to elective surgery versus emergency surgery for acute malignant colorectal obstruction. Int J Color Dis 31:561-570

45. Choi JM, Lee C, Han YM, Lee M, Choi YH, Jang DK, Im JP, Kim SG, Kim JS, Jung HC (2014) Long-term oncologic outcomes of endoscopic stenting as a bridge to surgery for malignant colonic obstruction: comparison with emergency surgery. Surg Endosc 28:2649-2655

46. Kavanagh DO, Nolan B, Judge C, Hyland JMP, Mulcahy HE, PR OC, Winter DC, Doherty GA (2013) A comparative study of shortand medium-term outcomes comparing emergent surgery and stenting as a bridge to surgery in patients with acute malignant colonic obstruction. Dis Colon Rectum 56:433-440

47. Dastur JK, Forshaw MJ, Modarai B, Solkar MM, Raymond T, Parker MC (2008) Comparison of short-and long-term outcomes following either insertion of self-expanding metallic stents or emergency surgery in malignant large bowel obstruction. Tech Coloproctol 12:51-55

48. Saida Y, Sumiyama Y, Nagao J, Uramatsu M (2003) Long-term prognosis of preoperative "bridge to surgery" expandable metallic stent insertion for obstructive colorectal cancer: comparison with emergency operation. Dis Colon Rectum

49. Rodrigues-Pinto E, Morais R, Coelho C, Pereira P, Repici A, Macedo G (2019) Bridge-to-surgery versus emergency surgery in the management of left-sided acute malignant colorectal obstruction - efficacy, safety and long-term outcomes. Dig Liver Dis 51:364-372

50. Quereshy FA, Poon JT, Law WL (2014) Long-term outcome of stenting as a bridge to surgery for acute left-sided malignant colonic obstruction. Color Dis 16:788-793

51. Gianotti L, Tamini N, Nespoli L, Rota M, Bolzonaro E, Frego R, Redaelli A, Antolini L, Ardito A, Nespoli A, Dinelli M (2013) A prospective evaluation of short-term and long-term results from colonic stenting for palliation or as a bridge to elective operation versus immediate surgery for large-bowel obstruction. Surg Endosc 27:832-842

52. Higgins JPT GS (2011) Cochrane handbook for systematic reviews of interventions version 5.1 (updated March 2011): the Cochrane Collaboration, 2011

53. Slim K, Nini E, Forestier D, Kwiatkowski F, Panis Y, Chipponi J (2003) Methodological index for non-randomized studies (minors): development and validation of a new instrument. ANZ J Surg 73: $712-716$

54. Council NHAM (2009) NHMRC levels of evidence and grades for recommendations for developers of guidelines Canberra: National Health and Medical Research Council

55. Datye A, Hersh J (2011) Colonic perforation after stent placement for malignant colorectal obstruction-causes and contributing factors. Minim Invasive Ther Allied Technol 20:133-140

56. Avlund TH, Erichsen R, Ravn S, Ciplys Z, Andersen JC, Laurberg S, Iversen LH (2018) The prognostic impact of bowel perforation following self-expanding metal stent as a bridge to surgery in colorectal cancer obstruction. Surg Endosc Other Interv Tech 32:328-336

57. Hayashi K, Jiang P, Yamauchi K, Yamamoto N, Tsuchiya H, Tomita K, Moossa AR, Bouvet M, Hoffman RM (2007) Real- time imaging of tumor-cell shedding and trafficking in lymphatic channels. Cancer Res 67:8223-8228

58. Lemoine L, Sugarbaker P, Van der Speeten K (2016) Pathophysiology of colorectal peritoneal carcinomatosis: role of the peritoneum. World J Gastroenterol 22:7692-7707

59. Sterne JA, Hernan MA, Reeves BC, Savovic J, Berkman ND, Viswanathan M, Henry D, Altman DG, Ansari MT, Boutron I, Carpenter JR, Chan AW, Churchill R, Deeks JJ, Hrobjartsson A, Kirkham J, Juni P, Loke YK, Pigott TD, Ramsay CR, Regidor D, Rothstein HR, Sandhu L, Santaguida PL, Schunemann HJ, Shea B, Shrier I, Tugwell P, Turner L, Valentine JC, Waddington H, Waters E, Wells GA, Whiting PF, Higgins JP (2016) ROBINS-I: a tool for assessing risk of bias in non-randomised studies of interventions. BMJ 355:i4919

60. Gietelink L, Wouters MW, Bemelman WA, Dekker JW, Tollenaar RA, Tanis PJ (2016) Reduced 30-day mortality after laparoscopic colorectal cancer surgery: a population based study from the Dutch Surgical Colorectal Audit (DSCA). Ann Surg 264:135-140

61. Ceresoli M, Allievi N, Coccolini F, Montori G, Fugazzola P, Pisano M, Sartelli M, Catena F, Ansaloni L (2017) Long-term oncologic outcomes of stent as a bridge to surgery versus emergency surgery in malignant left side colonic obstructions: a meta-analysis. J Gastrointest Oncol 8:867-876

62. Amelung FJ, de Beaufort HW, Siersema PD, Verheijen PM, Consten EC (2015) Emergency resection versus bridge to surgery with stenting in patients with acute right-sided colonic obstruction: a systematic review focusing on mortality and morbidity rates. Int $\mathrm{J}$ Color Dis 30:1147-1155

63. Lacy AM, Delgado S, Castells A, Prins HA, Arroyo V, Ibarzabal A, Pique JM (2008) The long-term results of a randomized clinical trial of laparoscopy-assisted versus open surgery for colon cancer. Ann Surg 248:1-7

64. Biagi JJ, Raphael MJ, Mackillop WJ, Kong W, King WD, Booth CM (2011) Association between time to initiation of adjuvant chemotherapy and survival in colorectal cancer: a systematic review and meta-analysis. JAMA 305:2335-2342

65. Young CJ, De-Loyde KJ, Young JM, Solomon MJ, Chew EH, Byrne CM, Salkeld G, Faragher IG (2015) Improving quality of life for people with incurable large-bowel obstruction: randomized control trial of colonic stent insertion. Dis Colon Rectum 58:838-849

66. Matsuda A, Miyashita M, Matsumoto S, Matsutani T, Sakurazawa N, Takahashi G, Kishi T, Uchida E (2015) Comparison of long-term outcomes of colonic stent as "bridge to surgery" and emergency surgery for malignant large-bowel obstruction: a meta-analysis. Ann Surg Oncol 22:497-504

67. Artinyan A, Orcutt ST, Anaya DA, Richardson P, Chen GJ, Berger DH (2015) Infectious postoperative complications decrease longterm survival in patients undergoing curative surgery for colorectal cancer: a study of 12,075 patients. Ann Surg 261:497-505

68. Nitta T, Kataoka J, Ohta M, Fujii K, Tominaga T, Inoue Y, Kawasaki H, Ishibashi T (2017) Clinical outcomes of selfexpandable metal stent (SEMS) placement as palliative treatment for malignant colorectal obstruction: a single-center study from Japan. Ann Med Surg (Lond) 19:33-36

69. Ptok H, Meyer F, Marusch F, Steinert R, Gastinger I, Lippert H, Meyer L (2006) Palliative stent implantation in the treatment of malignant colorectal obstruction. Surg Endosc Other Interv Tech 20:909-914

70. Small AJ, Baron TH (2008) Comparison of Wallstent and Ultraflex stents for palliation of malignant left-sided colon obstruction: a retrospective, case-matched analysis. Gastrointest Endosc 67:478-488

Publisher's note Springer Nature remains neutral with regard to jurisdictional claims in published maps and institutional affiliations. 